Winarno Fadjar Bastari dan John Geral Mesah: Rancang Bangun Interleaved Boost Converter Sebagai Perbaikan Kualitas Daya Pada Rangkaian Penyearah Satu Fasa Dengan Beban Induktif dan Resistif

\title{
RANCANG BANGUN INTERLEAVED BOOST CONVERTER SEBAGAI PERBAIKAN KUALITAS DAYA PADA RANGKAIAN PENYEARAH SATU FASA DENGAN BEBAN INDUKTIF DAN RESISTIF
}

\author{
Winarno Fadjar Bastari ${ }^{1}$, John Geral Mesah ${ }^{2)}$ \\ 1) 2) Program Studi Teknik Elektro, Fakultas Teknologi Industri \\ Universitas PGRI Adi Buana Surabaya \\ Email: winarnobastari1218@gmail.com
}

\begin{abstract}
Abstrak
Sumber tegangan searah didapat melalui rangkaian penyearah gelombang penuh satu fasa tidak terkendali dari sumber tegangan jala - jala PLN sebesar 220 Volt. Pemasangan kapasitor sebagai filter dengan nilai atau jumlah yang cukup besar dapat menyebabkan bentuk gelombang arus masukan menjadi tidak sinusoidal (terdistorsi) akibat dari harmonisa yang muncul sedangkan tegangan masukan dari jala - jala PLN berbentuk sinusoidal. Perbedaan bentuk gelombang tegangan dan arus masukan yang terjadi ini dapat berpengaruh pada nilai faktor yang dihasilkan. Berdasarkan masalah ini dibuatlah suatu penelitian mengenai perbaikan faktor daya menggunakan rangkaian Interleaved Boost Converter yang difungsikan sebagai rangkaian Power Factor Correction (PFC) dan regulator tegangan dengan metode pengaturan menggunakan logika Fuzzy. Rangkaian Interleaved Boost Converter ini dibuat bekerja pada kondisi Discontinues Conduction Mode (DCM) agar apapun beban yang dicatu pada rangkaian akan membuat sistem bersifat resistif. Sehingga diharapkan bentuk gelombang tegangan dan arus masukan sama yang akan menghasilkan nilai faktor mendekati nilai unity. Hasil dari penelitian ini adalah rangkaian Interleaved Boost Converter yang sudah dapat difungsikan sebagai rangkaian Power Factor Correction dan juga sebagai regulator tegangan. Nilai Faktor daya yang dihasilkan adalah sebesar 0.93 dimana jika dibandingkan dengan nilai faktor daya dari Power Supply Swicthing 48V sebesar 0.90 sudah jauh lebih baik.
\end{abstract}

Kata Kunci : faktor daya, interleaved boost converter, pfc.

\begin{abstract}
The unidirectional voltage source is obtained through an uncontrolled one-phase full wave rectifier circuit from the source of the mesh voltage - the grid is 220 Volt. Installation of capacitors as a filter with a value or a sufficiently large amount can cause the input current waveform to be not sinusoidal (distorted) due to the harmonics that appear while the input voltage from the net - the PLN grid is sinusoidal. The difference in voltage waveforms and input currents that occur can affect the value of the resulting factor. Based on this problem, a study was made on the improvement of power factors using a series of Interleaved Boost Converter which functioned as a series of Power Factor Correction (PFC) and voltage regulators with a setting method using Fuzzy logic. This Interleaved Boost Converter circuit is made to work in the condition of the Discontinues Conduction Mode (DCM) so that any load that is supplied to the circuit will make the system resistive. So it is expected that the voltage and input current waveforms will produce a factor value close to the unity value. The results of this study are the Interleaved Boost Converter series that can be used as a Power Factor Correction circuit and also as a voltage regulator. The value of the generated power factor is 0.93 where when compared to the value of the power factor of the 48V Power Supply Swicthing of 0.90 it's much better.
\end{abstract}

Keywords : power factor, interleaved boost converter, pfc. 

Winarno Fadjar Bastari dan John Geral Mesah: Rancang Bangun Interleaved Boost Converter Sebagai Perbaikan Kualitas Daya Pada Rangkaian Penyearah Satu Fasa Dengan Beban Induktif dan Resistif

\section{PENDAHULUAN}

Kualitas penyaluran daya listrik menjadi tuntutan untuk memperbaiki faktor daya dari sebuah rangkaian. Ini juga berlaku pada penyaluran daya DC. Sehingga kualitas daya dari penggunaan sebuah rangkaian penyearah satu fasa juga harus dijaga. Prinsip kerja dari rangkaian penyearah satu fasa adalah mengubah tegangan AC (arus bolak-balik) menjadi tegangan DC (arus searah). Untuk mencapai tegangan keluaran yang diinginkan, sebagai contoh untuk mengurangi ripple tegangan digunakan sebuah filter C (kapasitor) diujung / keluaran rangkaian penyearah. Namun penggunaan filter $\mathrm{C}$ pada rangkaian penyearah ini harus diimbangi dengan konsekuensi yang menyebabkan bentuk gelombang dari arus penyearah tersebut mengandung harmonisa. Hal ini akan menyebabkan kualitas daya pada rangkaian penyearah menjadi turun yang disebabkan oleh harmonisa dan suhu komponen elektronika meningkat (stress pada komponen elektronika).

Aturan tentang standar harmonisa juga menjadi salah satu pertimbangan untuk melakukan penelitian ini. Berdasarkan standar IEC 61000-3-2 yang digunakan beberapa negara di dunia, bahwa terdapat tetapan nilai harmonisa yang diijinkan pada suatu sistem kelistrikan. Standar yang biasa digunakan di Indonesia (PUIL 2000) juga menetapkan besaran nilai harmonisa yang diijinkan yaitu $10 \%$ dari tegangan nominal dan 5\% dari arus nominal berjalan. Maka dari itu diperlukan suatu rangkaian penyearah yang mempunyai standar kualitas daya yang tinggi (faktor daya mendekati nilai 1 dan harmonisa yang minim).

\section{METODE}

A. Rancangan Produk

Untuk memudahkan memahami rancangan awal alat dari Penelitian ini, maka blok diagram dibawah akan mewakili sistem dari Interleavedboost Converter yang akan dibuat.

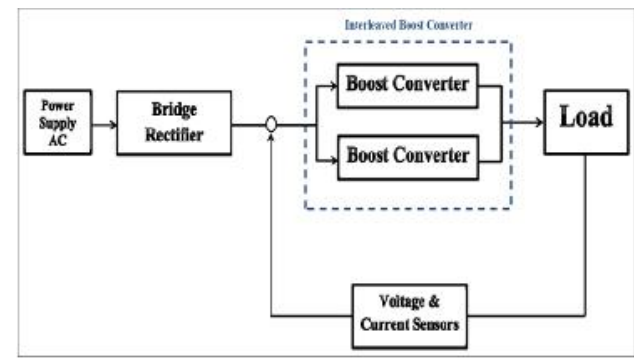

Gambar 1. Blok Diagram Awal Interleaved Boost Converter

Berikut ini adalah penjelasan fungsi dari masing - masing bagian blok diagram :

1) Power Supply AC, digunakan sebagai sumber tegangan yang nanti akan disearahkan terlebih dahulu sebelum masuk dalam rangkaian interleaved boost converter

2) Bridge Rectifier, digunakan untuk menyearahkan tegangan dari power supply AC. Didalamnya terdapat pula transformator CT untuk menurunkan tegangan yang akan disearahkan.

3) Interleaved Boost Converter, digunakan untuk mengubah tegangan DC keluaran dari Bridge Rectifier agar dapat diatur besar-kecilnya tegangan dan arus menuju beban / load.

4) Voltage \& Current Sensors, digunakan untuk mengukur tegangan dan arus dari beban yang akan diumpan-balikkan kedalam interleaved boost converter sebagai titik acuan untuk mengatur settling time kontrol logika fuzzy

Untuk rangkaian dasar dari Interleaved Boost Converter yang akan dibuat adalah sebagai berikut

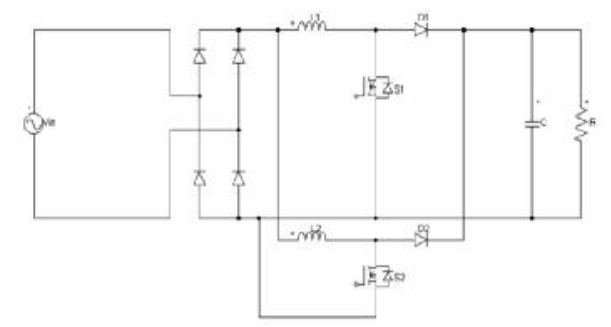

Gambar 2. Rangkaian Dasar Interleaved Boost Converter

Gambar diatas merupakan simulasi sederhana dari rangkaian interleaved boost converter. Dimana S1 dan S2 merupakan 
Winarno Fadjar Bastari dan John Geral Mesah: Rancang Bangun Interleaved Boost Converter Sebagai Perbaikan Kualitas Daya Pada Rangkaian Penyearah Satu Fasa Dengan Beban Induktif dan Resistif

MOSFET dengan tipe FQP50N06, yang akan digunakan untuk mengatur duty cycle pembangkitan sinyal PWM.

\section{B. Ruang Lingkup}

Untuk membatasi penelitian yang akan dilakukan, maka uang lingkup diatur sebagai berikut :

1) Rangkaian switching menggunakan Transistor MOSFET (Metal Oxide Semiconductor Field Effect Transistor) dengan tipe IRFP240

2) Rangkaian kontrol dan pembangkit sinyal PWM (Pulse Wave Modulation) menggunakan ARM STM32F407VG

3) Pemodelan sistem kontrol menggunakan metode logika Fuzzy Mamdani

C. Uji Produk

Prosedur pengujian pada produk:

1) Menguji Mikrokontroler arduino uno pada saat diprogram, apakah bisa menerima informasi dari sensor ultrasonic dan mengirim informasi timer ke motor AC.

2) Menguji sensor apakah dapat bekerja dengan baik yaitu dengan cara menyambungkan $\mathrm{v}+$ dan $\mathrm{v}$ - pada bagian port arduino uno dan sensor ultrasonic.

3) Menguji output pada motor AC, apakah bekerja dengan baik dengan cara menghubungkan power adaptor dengan sumber arus AC sehingga akan otomatis menyala dengan menggunakan melalui timer yang di program lewat arduino uno.

4) Menguji timer dan sensor, apakah dapat berfungsi dengan baik atau tidak.

5) Menguji secara keseluruhan tiap bagian komponen, apakah dapat bekerja dengan baik dengan cara mengoperasikan pakan udang otomatis.

Langkah-langkah dalam pengambilan data untuk jarak objek sebagai berikut:

1) Timer yang dikontrol dengan arduino uno akan tersambung ke motor AC.

2) Membuat tabel tabulasi hasil ke akuratan waktu timermya..

3) Sensor akan berfungsi jika pakan habis dengan jarak $40 \mathrm{~cm}$ ke arah bawah tabung dengan output yang menggunakan buzzer.

4) Motor AC akan menyala tiap 4 jam sekali dalam sehari.

Arduino adalah pusat komponen utama dan terpenting pada alat ini. Proyek ini adalah perangkat keras (hardware) dan perangkat lunak (software) interaktif mudah dan menarik. Pada alat ini arduino berfungsi sebagai program untuk mengatur timer dan sensor ultrasonik. Cara kerja alat ini dari arduino sebagai pengontrol timer yang dinputkan ke motor AC lalu akan memutar baling-baling sebagai penyebar pakan ke kolam. Dan sensor ultrasonik berfungsi Isebagai pengontrol pakan jika pakan yang di dalam tabung itu akan segera habis.

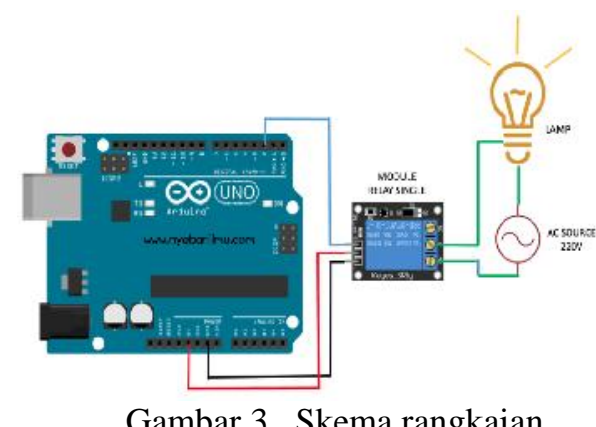

Gambar 3. Skema rangkaian

\section{HASIL DAN PEMBAHASAN}

A. Perangkat keras (hardware)

Alat pakan ikan otomatis berbasis Mikrokontroler ARDUINO UNO ini bekerja berdasarkan timer dan sensor ultrasonic. Dan diubah menjadi tegangan digital oleh ADC dimulai dari kerja timer dalam hal ini sebagai pengganti tenaga manusia.

Selanjutnya akan diolah input timer di dalam ADC untuk output tegangan yang dikeluarkan dalam bentuk gerak melalui motor AC. Sedangkan untuk output ke sensor menggunakan rangkaian DAC.

\section{B. Perangkat lunak (software)}

Sebelum membuat sebuah Program maka terlebih dahulu membuat diagram alur atau Flowchart, yang dibuat dan disesuaikan dengan cara kerja perancangan 
Sistem sehingga akan di dapatkan Output yang sesuai dengan yang diinginkan.

Perangkat lunak (software) yang digunakan dalam sistem timbangan digital ini adalah bahasa pemrograman BASIC juga bisa dengan bahasa C. Fungsi utama dari perangkat lunak ini yaitu :

1) Menerima output dari arduino yang berupa timer di outputkan ke motor AC. kemudian data tersebut diolah pada internal ADC mikrokontroler berupa timer digital dan kemudian di salurkan ke timer dan sensor ultrasonic.

2) Mengolah data digital yang akan dikonversi menjadi data analog oleh DAC sebagai output pada buzzer berupa suara Selanjutnya akan diolah input timer di dalam ADC untuk output tegangan yang dikeluarkan dalam bentuk gerak melalui motor AC. Sedangkan untuk output ke sensor menggunakan rangkaian DAC.

\section{PEMBAHASAN}

Alat ini menggunakan sensor ultrasonik dengan outputnya bell, dan timer melalui arduino yang bertujuan untuk menggerakkan motor AC. Yang bertujuan untuk mempermudah petani tambak dalam hal memberi pakan udang.

Pada penyajian data ini akan dibahas tentang langkah-langkah perancangan alat pada pakan udang otomatis dan pengujian alat. Tujuan dari perancangan dan uji coba alat ini adalah untuk mengetahui fungsi timer dan sensor ultrasonik terhadap alat tersebut

Kalau menggunakan tenaga manusia, maka akan tidak efisien dan efektif. Kalau pakai alat ini, bisa pastikan misalnya waktu 1 menit untuk motor ON itu pasti yang keluar tergantung putaran motor nya.

Alat ini terdiri dari sejumlah komponen yakni galon air isi ulang sebagai tempat menyimpan pakan, mikrokontroler sebagai "otak" yang akan menentukan kapan dan berapa banyak pakan akan disebar, pipa sebagai dasar pijakan alat di atas tambak dan ada juga kontroler dengan output nya motor sebagai penggerak alat pakannya.
Jadi nanti petani tambak tinggal menunggu bunyi sirene itu tanda sebagai pakan yang ada pada galon akan habis. Alatnya itu ditaruh di tengah tambak sehingga kalau sudah habis bisa di isi kembali oleh petani tersebut.

Keunggulan alat ini adalah sistem spray dalam pelaksanaan penyebaran pakan sehingga bisa menjangkau area lebih luas dan merata di seluruh tambak, juga akan lebih efisien dan fleksibel jika dibandingkan dengan menggunakan tenaga petani tambak secara manual. Jangkauan sebaran pakan juga bisa menyampai 4 meter, jadi akan mempermudah pekerjaan petani tambak dan kelak bisa meningkatkan hasil panen.

\section{KESIMPULAN}

Dari hasil pengujian alat dan analisa yang telah dilakukan, maka dapat disimpulkan bahwa :

1. Rangkaian Interleaved Boost Converter yang dirancang dan dibuat pada penelitian ini dapat berfungsi sebagai Power Factor Correction dengan baik dengan nilai faktor daya yang dihasilkan sebesar 0.93.

2. Rangkaian Interleaved Boost Converter yang juga digunakan sebagai regulator tegangan dapat mempertahankan tegangan keluaran sebesar 48 Volt dengan sistem fuzzy logic controller.

3. Desain power factor correction dengan menggunakan rangkaian Interleaved Boost Converter ini dapat mengurangi nilai THD Arus dari $39.0 \%$ (Sistem Tanpa Pengaturan Tegangan Output) ke nilai 33.5\% (Sistem Dengan Pengaturan Tegangan Output) dan nilai ini jauh lebih baik dibandingkan dengan Power Supply Switching yang banyak digunakan dengan nilai THD Arus 58\% hingga $60 \%$.

\section{UCAPAN TERIMA KASIH}

Penelitian ini telah mendapatkan dukungan dari Dekan, Ketua Program Studi Teknik Elektro Fakultas Teknologi Industri, Universitas PGRI Adi Buana Surabaya. 
Winarno Fadjar Bastari dan John Geral Mesah: Rancang Bangun Interleaved Boost Converter Sebagai Perbaikan Kualitas Daya Pada Rangkaian Penyearah Satu Fasa Dengan Beban Induktif dan Resistif

\section{DAFTAR PUSTAKA}

For a, Rony HR. (2017). Pengantar Pemodelan Kendali. Surabaya : Adi Buana University Press. Nazir M. (2008). Design of a Single Phase Unity Power Factor Switch Mode Power Supply with active power factor correction. In W. Gerald, H. Zuoqui, \& B. Norman (Eds.). IEEE TRANSACTION ON POWER ELECTRONICS 2008 (pp. 109 - 121). Ohaio : IEEE Press.

Ned Mohan, Tore M. Undeland, \& William P. Robbin. (1989). Power Electronics: Converter, Application, and Design. Singapore : Wiley.

Phattanasak M, Chunkag V. (2004). Paralleling of single phase AC/DC converter with power factor correction. In B. Johansen (Ed). Power Electronics Specialists Conference 35th Annual IEEE (pp. 128 - 140). Philadelpia : EJ Press.

Rashid M. (1999). Elektronika Daya, Power Electronic : Circuit, Device and Aplication. Jakarta : PT. Prenhallindo

R.J. Wai \& R.Y. Duan. (2005). Converter uses for power factor correction. In D. Juan (Ed). Power Electronics Specialists Conference 36th Annual IEEE (pp. 118 - 140). Philadelpia : EJ Press.

Tommy Aditya. (2016). Rancang Bangun Konverter Photovoltaic dan Pentaksiran Daya. In Rahma Erajaya (Ed). Jurnal Penelitian Tahunan Politeknik Elektronika Negeri Surabaya (pp 13 - 30). Surabaya : EEPIS Pres.

Yao G., Chen A., \& Xiangning H. (2007). Soft Switching Circuit for Interleaved Boos Converters. In J. Hudson (Ed.). IEEE Transaction on Power Electronics 2008 (pp 75 - 99). Ohaio : IEEE Press.

Zao Q. \& Lee F.C. (2003). High Efficiency, High Step Up DC-DC Converter. In B. Hudson (Ed). IEEE Transaction on Power Electronics 2003 (pp 87 - 97). Philadelpia : IEEE Press 